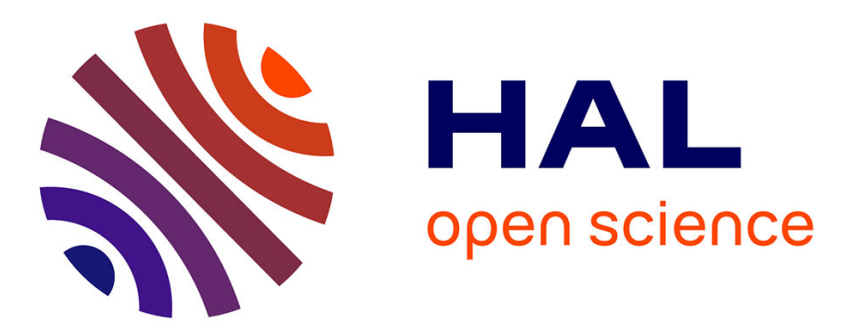

\title{
Rising temperature reduces divergence in resource use strategies in coexisting parasitoid species.
}

Cécile Le Lann, Bertanne Visser, Maëlle Mériaux, Joffrey Moiroux, Joan van Baaren, Jacques J.M. van Alphen, Jacintha Ellers

\section{- To cite this version:}

Cécile Le Lann, Bertanne Visser, Maëlle Mériaux, Joffrey Moiroux, Joan van Baaren, et al.. Rising temperature reduces divergence in resource use strategies in coexisting parasitoid species.. Oecologia, 2013, 174 (3), pp.967-977. 10.1007/s00442-013-2810-9 . hal-00906723

HAL Id: hal-00906723

https://hal-univ-rennes1.archives-ouvertes.fr/hal-00906723

Submitted on 20 Nov 2013

HAL is a multi-disciplinary open access archive for the deposit and dissemination of scientific research documents, whether they are published or not. The documents may come from teaching and research institutions in France or abroad, or from public or private research centers.
L'archive ouverte pluridisciplinaire HAL, est destinée au dépôt et à la diffusion de documents scientifiques de niveau recherche, publiés ou non, émanant des établissements d'enseignement et de recherche français ou étrangers, des laboratoires publics ou privés. 


\section{Rising temperature reduces divergence in resource use strategies in}

\section{coexisting parasitoid species}

Cécile Le Lann ${ }^{1,3 *}$, Bertanne Visser², Maëlle Mériaux³ ${ }^{3}$ Joffrey Moiroux ${ }^{4,5}$, Joan van Baaren $^{3}$, Jacques J.M. van Alphen ${ }^{6,7}$ and Jacintha Ellers ${ }^{1}$

${ }^{1}$ Department of Ecological Science, VU University Amsterdam, De Boelelaan 1085, $1081 \mathrm{HV}$, Amsterdam, The Netherlands

${ }^{2}$ Institut de Recherche sur la Biologie de l'Insecte, Université de Tours, IRBI UMR CNRS 7261, Av. Monge, 37200, Tours, France

${ }^{3}$ Unité Mixte de Recherche CNRS 6553, ECOBIO, Université de Rennes 1, 35042 Rennes Cedex, France

${ }^{4}$ Institut de Recherche en Biologie Végétale, Département de sciences biologiques, Université de Montréal, 4101 Sherbrooke Est Montréal, Québec, Canada H1X 2B2

${ }^{5}$ Horticultural Research and Development Centre, Agriculture and Agri-Food Canada, 430 Boulevard Gouin, St-Jean-sur-Richelieu, Québec, Canada J3B 3E6

${ }^{6}$ Center for Biodiversity Naturalis, p.o. box 9517, 2300 RA Leiden, The Netherlands

${ }^{7}$ IBED, University of Amsterdam, p.o. box 94248, 1090 GE Amsterdam, The Netherlands

*Correspondence: Tel.: +31 205983808; fax: +31 205987123. E-mail: cecile.lelann@univ-rennes1.fr / cecile.lelann@gmail.com

Running title: Rising temperature reduces trait divergence in coexisting species..$^{\dagger}$

${ }^{\dagger} \mathrm{CLL}, \mathrm{BV}, \mathrm{JvB}, \mathrm{JvA}$ and JE conceived and designed the experiments. CLL, BV, MM and JM performed the experiments. CLL analyzed the data. CLL and JE wrote the manuscript; other authors provided editorial advice. 


\section{ABSTRACT}

Coexistence of species sharing the same resources is often possible if species are phylogenetically divergent in resource acquisition and allocation traits, decreasing competition between species. Developmental and life history traits related to resource use are influenced by environmental conditions such as temperature, but thermal trait responses may differ among species. An increase in ambient temperature may, therefore, affect trait divergence within a community and potentially species coexistence. Parasitoids are interesting models to test this hypothesis, because multiple species commonly attack the same host, and employ divergent larval and adult host use strategies. In particular development mode (arrested or continued host growth following parasitism) has been recognized as a major organizer of parasitoid life histories. Here we used a comparative trait-based approach to determine thermal responses of development time, body mass, egg load, metabolic rate and energy use of the coexisting Drosophila parasitoids Asobara tabida, Leptopilina heterotoma, Trichopria drosophilae and Spalangia erythromera. We compared trait values between species and development modes, and calculated trait divergence in response to temperature, using functional diversity indices. Parasitoids differed in their thermal response for dry mass, metabolic rate and lipid use throughout adult life, but only teneral lipid reserves and egg load were affected by developmental mode. Species-specific trait responses to temperature were probably determined by their adaptations in resource use (e.g. lipogenesis or ectoparasitism). Overall, trait values of parasitoid species converged at the higher temperature. Our results suggest that local effects of warming could affect host resource partitioning by reducing trait diversity in communities.

Keywords: climate change, community, idiobiont, insect, koinobiont 


\section{Introduction}

Many mechanisms for stable coexistence of species rely on ecological and evolutionary differences that reduce competition through reduced niche overlap (Chase and Leibold 2003). For instance, coexisting species may possess divergent life history trade-offs between main functions, such as development, reproduction and survival, reflecting differential acquisition and allocation of the shared resources (Pelosse et al. 2007; Harvey 2008; Jervis et al. 2008; Le Lann et al. 2012). Community assembly may favour phylogenetically distant species that possess dissimilar traits, leading to decreased competition within communities (MacArthur and Levins 1967; Tilman 1982). However, various developmental and life history traits related to resource use show considerable phenotypic plasticity (Violle et al. 2012). The magnitude of intraspecific trait variation caused by phenotypic plasticity can be equally large in magnitude as interspecific trait variation (Canham et al. 1999; Valladares et al. 2000; Jervis et al. 2001), as was shown for physiological and morphological traits of related plant species in response to light conditions (Valladares et al. 2000). A change in environmental conditions can therefore cause a drastic change in the trait values and phenotypic plasticity should be taken into account in trait-based comparisons aiming to explain species coexistence (Berg and Ellers 2010).

Due to global warming, average temperatures have risen by about $0.8^{\circ} \mathrm{C}$ since the early $20^{\text {th }}$ century and a further increase of about $3^{\circ} \mathrm{C}$ is predicted during the 21 st century (IPCC 2007). These figures mask the fact that at local and regional scales warming effects can even be more intense, as is predicted for Western Europe (IPCC 2007). In ectotherms, ambient temperature is a major determinant of intraspecific trait variation throughout various life stages (Atkinson 1994; Angilletta et al. 2004). To persist, species thus need to be able to cope with challenging thermal changes (Hance et al. 2007; van Baaren et al. 2010). However, 
there are large interspecific differences in thermal responses among species within a community (Berg et al. 2010). As a consequence, the regional or local effects of global warming may alter trait divergence among co-occurring species sharing the same resources, and ultimately affect the ability of species to coexist.

Parasitoid insects are excellent model organisms to study questions concerned with the effect of temperature on trait divergence and species coexistence. Parasitoids develop in or on other arthropods, limiting larval resource acquisition to the quantity of resources that is contained within a single host. Numerous parasitoid species that commonly attack the same host species show divergent larval and adult host use strategies, such as host stage attacked (Price 1972, 1974; Askew and Shaw 1986), level of host specialization (Harvey and Witjes 2005; Harvey et al. 2008), and life history traits, such as rate of metabolic expenditure and lipid reserves (Pelosse et al. 2007; Le Lann et al. 2012), which are primarily used for life span and reproduction (Ellers and van Alphen 1997). The trait divergence within parasitoid communities is thought to facilitate coexistence among species.

Much of the divergence in traits relating to host use can be captured by the contrast between two larval development modes: idiobiosis and koinobiosis (Harvey et al. 2013). Idiobiont parasitoids fix the developmental stage of their host at the time of parasitism, which causes host resources to gradually decline in quality during development of the parasitoid. In contrast, koinobiont parasitoids allow hosts to develop after parasitism and can manipulate feeding behaviour and growth of their hosts to increase resources availability (Askew and Shaw 1986; Vinson 1988; Godfray 1994; Visser and Ellers 2008). Comparative analyses showed that in general koinobionts attack early larval host instars, produce small yolk-poor (hydropic) eggs, have higher maximum egg loads, higher daily rates of oviposition, higher lifetime fecundities, and longer pre-adult, but shorter adult life spans than idiobionts (Blackburn 1991a,b; Mayhew and Blackburn 1999; Harvey 2005; Traynor and Mayhew 2005; 
Jervis et al. 2008, 2012). While development mode is a fixed trait for species, many associated life history traits are highly sensitive to temperature, and it is unknown if the dichotomy in trait values associated with development mode is sensitive to temperature.

In this study we use a comparative approach to test if differential thermal responses to an increase in ambient temperature can lead to a reduction in trait divergence within a community of parasitoid species sharing similar host resources. For this purpose, we used a small community composed of two koinobiont and two idiobiont parasitoid species that all attack the fruit fly, Drosophila melanogaster (Diptera: Drosophilidae) during summer (Carton et al. 1986; Fleury et al. 2009). For each species, we assessed thermal responses of traits by measuring development time, body mass, teneral egg production and lipid reserves as well as their metabolic rate and lipid use during adult life at two temperatures. We tested for differences in traits and trait plasticity between species and between larval development modes. Finally, we examined overall trait divergence of species within this community at different temperatures, using classical functional trait diversity indices (Villéger et al. 2008; Pavoine and Bonsall 2001), to test if niche differentiation is maintained or if an increase in temperature leads to trait convergence.

\section{Materials and Methods}

\section{Study site and sampling}

The host D. melanogaster originated from laboratory strains maintained at the Institute of Biology in Leiden since 1966. Parasitoid species were collected within two time periods: 1) from June to August 2008, and 2) from June to July 2011, in Vieux-Vy sur Couesnon in France $\left(48^{\circ} 21^{\prime} 05^{\prime \prime} \mathrm{N}, 1^{\circ} 29^{\prime} 16^{\prime \prime} \mathrm{W}\right)$ using 30 open traps (i.e. a plastic container with a 3 -cm diameter aperture covered with a mesh with $2 \mathrm{~mm}$ openings) baited with bananas and yeast. Bananas were retrieved, replaced by new ones every two weeks and then placed at room 
temperature until parasitoid emergence. Each trap was colonised and species identity determined to start cultures with more than 10 individuals per species. In Western Europe, the parasitoids sampled are part of a natural small community composed mainly of the larval koinobionts: Asobara tabida (Hymenoptera: Braconidae) and Leptopilina heterotoma (Hymenoptera: Eucoilidae), and the pupal idiobionts: Trichopria drosophilae (Hymenoptera: Diapriidae) and Spalangia erythromera (Hymenoptera: Pteromalidae) (Carton et al. 1986; Fleury et al. 2009). Species-specific biological and life history traits reported in the literature have been summarized in Table 1 .

\section{Rearing and experimental conditions}

For rearing and experiments, hosts and parasitoids were kept at 20 and $23 \pm 1^{\circ} \mathrm{C}$ to mimic warmer predicted average summer temperatures (averages for sampling years 2008 and 2011 were between 16 and $17^{\circ} \mathrm{C}$ at collection sites; Météo France, Vieux-Vy sur Couesnon) (IPCC 2007). Experimental temperatures were further chosen to ensure that all parasitoid species could develop, as higher average temperatures severely affect survival of immature parasitoids (van Strien-van Liempt 1983; Le Lann, unpublished data). For each temperature regime, other abiotic conditions remained similar: $70 \pm 10 \% \mathrm{RH}$ and a 12:12h light:dark regime, with the exception of $A$. tabida which was reared under a $16: 8 \mathrm{~h}$ light:dark regime at $20^{\circ} \mathrm{C}$ to prevent entry into diapause (Carton et al. 1986; Fleury et al. 2009). Hosts were reared under these conditions for at least two generations before use in experiments.

Drosophila melanogaster flies were allowed to lay eggs on standard Drosophila food medium (Visser et al. 2010) during one day, after which adults were removed. After $D$. melanogaster egg laying, second instar larvae and newly formed pupae (one day-old) were collected for larval and pupal parasitoid rearing, respectively. For all parasitoid species, females aged 6-10 days were provided with hosts in separate glass jars on an agar-Nipagine 
substrate. Only for larval parasitoids, the substrate was supplemented with a baker's yeast suspension to allow Drosophila larvae to feed.

To ensure a sufficient number of progeny for all experiments, 20-30 foundresses per parasitoid species and temperature were used. About 200 second instar Drosophila larvae were offered daily to each $L$. heterotoma and A. tabida females whereas each $T$. drosophilae females was offered 60 pupae each day, during three consecutive days. Due to the slow oviposition rate of $S$. erythromera (with a maximum of 4 eggs laid per day; Carton et al. 1986), females were offered 20 hosts for oviposition, which were replaced the first day and then twice every two days during six days. Females were fed ad libitum with acacia honey. The ensuing progeny was then used for trait measurements.

\section{Trait measurements}

Development time - At each temperature, development time was recorded and vials were checked twice a day for newly emerged females $(\mathrm{N}=5-89$ females per species per temperature). These females were divided into three groups for further measurements. The first group was then used to measure egg load, and lipid content at emergence, the second group at 1 day-old to measure metabolic rate and the last group for measuring lipid content at 7 days-old. Adult females of the first group were unfed and females of the second and third group were fed ad libitum with acacia honey. Females were frozen and stored at $-20^{\circ} \mathrm{C}$ until further analyses.

Teneral resource allocation - At emergence, egg load, lipid content and dry mass of each female $(\mathrm{N}=5-46$ females per species per temperature) were determined following the method of Ellers (1996). In short, a female was placed in a drop of distilled water on a small piece of cover slip of known weight and dissected under a binocular (940, Olympus SZX9) to extract the ovaries. Eggs were counted under a microscope (94, Olympus BH2). The piece of cover 
slip with the dissected body of the female was dried for 3 days at $80^{\circ} \mathrm{C}$ and weighed (MetlerToledo UMX2, micro-electrobalance, sensitivity: $0.1 \mu \mathrm{g}$ ). We obtained the dry weight of the female by subtracting the weight of the cover slip. Lipids were extracted by placing the cover slip in a vial containing $4 \mathrm{ml}$ of ether. After $24 \mathrm{~h}$, the cover slip was washed with fresh ether and re-dried for 3 days at $80^{\circ} \mathrm{C}$. The dry weight of the female was then determined and lipid content calculated as the difference in dry weight before and after ether extraction.

Resting metabolic rate - To measure the resting metabolic rate (RMR) of the wasps, flowthrough respirometry (Sable Systems International) was used. Measurements were performed without light (from 10:30 am to $16: 30 \mathrm{pm}$ ). Females were placed individually in small cylindrical chambers in a climate room regulated at 20 or $23 \pm 1^{\circ} \mathrm{C}$. For each species at each temperature, the metabolic rate of 20 females, fed with honey and aged 12 to $24 \mathrm{~h}$, was measured (except for L. heterotoma $20^{\circ} \mathrm{C}: \mathrm{N}=28$ and $T$. drosophilae $23^{\circ} \mathrm{C}: \mathrm{N}=17$ ). Their $\mathrm{CO}_{2}$ production was measured with a $\mathrm{CO}_{2}$ infrared analyser (CA-10A Carbon Dioxide Analyzer, Berlin, Germany). Temperature and flow rates were maintained with a temperature controller (Pelt-5) and a mass flow valve controller (MFC-2), respectively. Ambient air was drawn and $\mathrm{CO}_{2}$ and water were scrubbed with a Drierite-Ascarite column. Four cycles of records of $85 \mathrm{~min}$ each, with a sample every second, were performed for each female and were automatically transformed from ppm to $\mu \mathrm{L}-\mathrm{CO}_{2}$ per hour by Expedia software (Sable Systems, Berlin), taking into account flow rate, temperature and barometric pressure. We considered the average of three mean recordings as a measure of the RMR for each individual. The first measurement was left out and taken as an acclimation period to allow the parasitoids to accustom to their new environment. The value of the blank tube was subtracted from each measured value. As fresh body mass is known to be highly positively correlated with metabolic rate in parasitoids (Le Lann et al. 2011b, 2012), females were frozen and stored at $-20^{\circ} \mathrm{C}$ at the end of the experiment and their fresh body mass determined using a 
micro-electrobalance (Mettler Toledo XP2U, precision: $0.1 \mu \mathrm{g}$ ). Mass-corrected RMR was calculated by dividing RMR by fresh body mass.

Lipid use during adult life - Temporal variation in lipid content between emergence and seven days was compared between species at both temperatures. Lipid contents of newly emerged females were measured using the method of Ellers (1996) (i.e. the same females used to measure teneral resources: $\mathrm{N}=5-46$ females per species per temperature). Lipid content of non-dissected 7-day old females were measured using the method of Visser et al. (2010) $(\mathrm{N}=$ 4-62 females per species per temperature). This method is derived from Ellers (1996), but individuals are freeze-, rather than oven-dried, for 2 days before and after ether extraction.

\section{Statistical analyses}

To test for differences in thermal response of the traits described above, linear mixed models (LMMs) were performed using temperature, larval developmental mode, species within development mode, and their interactions as fixed factors with foundress female nested within species as a random factor.

Dry mass at emergence, development time and mass-corrected RMR were analyzed including only the factors listed above. To analyze lipid content and egg load at emergence, dry mass was included as an additional covariate. Finally, temporal variation in lipid content during adult life was analyzed using dry mass as a covariate and time (i.e. emergence or seven days-old) as an additional factor along with interactions between time and fixed factors described above.

Data were either cube root (lipid content) or log (metabolic rate) transformed to meet assumptions of residual normality and homoscedasticity. $P$-values reported were those of the saturated models that contained all factors and their interactions. However, covariates and their interactions with the factors were removed from the models when they were not 
significant (Dash signs, Table 2). All analyses were performed with IBM SPSS Statistics 20.0 (SPSS, Inc., 2012, Chicago,IL, ww.spss.com).

Finally, to examine if trait divergence of species changed with temperature, we considered species exposed to the two different temperatures as two different communities, and calculated two indices of functional diversity for each community. First, the functional richness index (FRic) (Villéger et al. 2008) reflects the range of functional trait variability in a given species community. Second, Rao's quadratic entropy index of diversity (RaoQ) (Pavoine and Bonsall 2011) expresses the sum of dissimilarities in the trait space among all possible pairs of species weighted by the product of relative species abundance. Both indices vary between 0 and 1 . The abundance of each species was fixed at 1 for each temperature, because quantifying changes in community structure or composition was not the purpose of our study. Functional diversity estimates were based on averaged values of the six traits measured in this study: development time, teneral dry mass, lipid content, egg load, masscorrected RMR, and the amount of lipid used or produced between emergence and 7 days. We computed these indices using the standard "FD" package (Laliberté and Shipley 2011) in R version 2.12.1 (R Development Core Team 2010).

\section{Results}

\section{Thermal plasticity in development and teneral resource allocation}

Dry mass and development time decreased with increasing temperature (Fig. 1a and b, Table 2). Dry mass responses to temperature differed between species within developmental mode but not between developmental modes (Fig. 1a; Table 2), indicating that temperature affected dry mass in a similar way in both koinobionts and idiobionts (Table 2). Idiobionts had a longer development time than koinobionts and species differed within development 
mode (Fig. 1b) but there was no significant interaction between temperature and development mode or species (Table 2).

Temperature differentially affected lipid content of koinobionts and idiobionts, with a stronger decrease in lipid content in koinobionts (Fig. 1c, Table 2). Lipid content at emergence increased with dry mass and was higher in koinobionts than idiobionts (Fig. 1c). Additionally, there was an interaction between development mode and dry mass, meaning that dry mass affected lipid content of koinobionts more than that of idiobionts (Fig. 1c). There was no significant interaction between temperature and species within development mode (Table 2).

There was a significant interaction between temperature and development mode: the number of eggs of koinobionts decreased with increasing temperature whereas the egg load of idiobionts was more or less constant across temperatures (Fig. 1d, Table 2). Egg load decreased with decreasing dry mass and differed between development modes, with koinobiont species having a higher number of eggs at emergence than idiobionts (Table 2). Species within development modes also differed in their number of eggs (Fig. 1d).

\section{Thermal plasticity in energy use throughout adult life}

In general, mass-corrected RMR increased at a higher temperature and idiobionts had a higher RMR than koinobionts (Table 2). This was mainly due to an effect of species within development modes with $S$. erythromera having a higher RMR than all species and differing from the others in its response to temperature by having a lower RMR at the highest temperature (Fig. 2a). There was no interaction between development modes and temperature (Table 2).

Between emergence and seven days, lipid content co-varied positively with dry mass and differed between development modes and species. There was no effect of time or 
temperature as a main factor, but there were several significant interactions with dry mass and development modes indicating that these factors did have an effect on lipid content. The response of lipid content to temperature and time was largely species-specific, as indicated by the significant interactions between species within development modes and temperature or time (Table 2) (Fig. 2b).

\section{Effect of temperature on community trait diversity}

Overall, species traits showed convergence at higher temperature, as both indices were lower at $23^{\circ} \mathrm{C}$ than at $20^{\circ} \mathrm{C}$, indicating a reduction in divergence (Fig. 3).

\section{Discussion}

Temperature-induced plasticity affects resource use and life history traits in various organisms, such as plants (Coleman and Bazzaz 1992), birds (Cavieres and Sabat 2008), mammals (Reale et al. 2003), and especially ectotherms such as Daphnia (Mitchell et al. 2004), insects (Bochdanovits and De Jong 2003; Colinet et al. 2007; Geister et al. 2009) and lizards (Luo et al. 2010). Here, we demonstrated that thermal plasticity in key resource acquisition and allocation traits causes a reduction in overall trait divergence within the community.

In ectotherms, the effect of temperature is best-documented for body size, with about $80 \%$ of the species following the temperature size rule (TSR) (i.e. individuals have larger body sizes at lower temperatures through longer development times; Atkinson 1994, Angilletta et al. 2004). In parasitoids, the majority of species achieve a larger body size at low temperatures (Eliott et al. 1995; Bazzocchi et al. 2003; Li and Mills 2004; Colinet et al. 2007; Foray et al. 2011; Le Lann et al. 2011b; Wu et al. 2011; Baffoe et al. 2012; Dosdall et al. 2012), although some idiobionts do not follow the TSR when host resources are limiting (i.e. 
constrained the quantity of energy that can be acquired by the parasitoid larva; Boivin 2010; Nealis et al. 1984). In our study, all species responded classically to increased temperature, because they developed faster at the high temperature and reached a smaller adult body size.

Warmer developmental temperatures can also reduce Drosophila host size (Atkinson 1994; Bochdanotvits and De Jong 2003) and thereby may affect parasitoid development and body size differently according to their development mode (Cohen et al. 2005; Harvey 2005). Here, we did not find differential thermal responses in growth and body size between koinobiont and idiobionts. Our results revealed a species-specific thermal response in body size and the decrease in body size was most pronounced for S. erythromera, increasing divergence in body size of the community at the higher temperature. Body size divergence is frequently observed in coexisting species and may cause resource partitioning depending on the impact on foraging behaviors and prey size (Petchey et al. 2008). Parasitoid body size was previously shown to be positively correlated with dispersal distance (Ellers et al. 1998) and a decrease in body size may therefore cause a more localized host searching behavior, affecting the spatial distribution of parasitism risk of hosts. Increased body size divergence in the Drosophila parasitoid community may thus affect the structure of the food web through changes in host-parasitoid population dynamics (Cohen et al. 2005; Petchey et al. 2008).

Previous comparative work has identified development mode as a major organizer of parasitoid life histories (Mayhew and Blackburn 1999), and our results confirm the relevance of this dichotomy for understanding intraspecific trait variation in important host use traits. Despite much variation at the species level, our results indeed show that allocation of larval resources to adult lipid reserves and egg load, two niche-defining life history traits among parasitoids (Ellers et al. 2000), differ between development modes. Overall, koinobionts had a higher number of eggs at emergence than idiobionts, confirming earlier differences in egg load found between development modes (Mayhew and Blackburn 1999). Higher fecundities 
are generally found in species attacking younger host stages (Price 1973; Blackburn 1991a, b; Jervis et al. 2012); and our results conform to this as our two koinobiont species attack young Drosophila larvae whereas the two idiobiont species attack older pupal hosts. In our study, koinobionts also had larger teneral lipid reserves than idiobionts. Larger lipid reserves are known to be associated with higher longevity in the koinobionts A. tabida and L. heterotoma (Ellers et al. 1998; Eijs and van Alphen 1999), suggesting that in this specific community these koinobionts may not have shorter lifespan than pupal idiobionts, as this pattern is observed for a broader range of species (Mayhew and Blackburn 1999).

In addition to the difference in trait values associated with development mode, we also found that differences in thermal responses of key traits were partly associated with development mode. Koinobiont parasitoids are expected to have stronger thermal responses, since they kill their hosts only when their development is completed. This thus incurs a double cost from elevated temperatures: through a reduced performance of their host as well as a reduction in their own performance (Hance et al. 2007). Indeed, only for egg load and lipid reserves at emergence this pattern is observed. At higher temperature we observe a decrease in egg load and lipid reserves of koinobionts at emergence, in contrast to idiobionts that show a constant egg load and no consistent change in lipid reserves across temperatures. Thermal conditions can therefore reduce divergence of life histories of koinobionts and idiobionts through differential plasticity of key traits, potentially altering their niche complementarity.

In fact, many parasitoid species are constrained by the quantity of teneral lipid reserves as they cannot accumulate additional lipids during adult life (Visser and Ellers 2008; Visser et al. 2010) due to their inability to synthesize lipids de novo from dietary sugars (Visser et al. 2012). Only the larval koinobiont parasitoid L. heterotoma is capable of lipogenesis (Visser et al. 2010), as it accumulates lipids between emergence and seven days at 
the lower temperature, suggesting a different resource use strategy during adult life (Le Lann et al. 2012). However, at the higher temperature no lipid accumulation was seen in $L$. heterotoma (nor in the other species). Under warm conditions, lipids are probably consumed at a higher rate because metabolic rate typically increases with temperature (Gillooly et al. 2001), resulting in constant lipid levels over time.

For the thermal response of metabolic rate no effect of developmental mode is found. Nevertheless, divergent thermal responses of metabolic rate are found between species, with S. erythromera having a 4-fold higher mass-corrected RMR than the other species and a decrease of its RMR with temperature. A possible explanation for the high RMR may be that S. erythromera is adapted to cooler temperatures, for instance because of activity earlier in the season (Le Lann et al. 2011a). To sustain physiological processes at lower temperatures more mitochondria and enzymes are needed (Hochachka and Somero 2002), resulting in temperature compensation (Clarke 1993). Differential use of microhabitats with cooler temperatures may have promoted sympatry ( $\mathrm{Qu}$ et al. 2011), as is found in other species; however, such thermal niches may be lost under climate warming. More studies are needed to describe temperature effects on Drosophila parasitoid communities and particularly the abundance and activity of idiobiont species over seasons (Fleury et al. 2009).

Niche complementarity has often been invoked as a mechanism for species coexistence (Ashton et al. 2010). Competition for shared resources can be weakened through divergence in functional traits within communities. Although many studies have addressed spatial and temporal patterns in trait diversity, for instance by comparing communities across latitudinal or environmental gradients (Irz et al. 2007; Carmona et al. 2012), to our knowledge, this is the first study to quantify community changes in trait diversity through plastic responses to changing environmental conditions. Our experimental approach showed that development time, egg load at emergence, RMR and the proportion of lipids used 
converge in a drosophila parasitoid community, whereas teneral dry mass and lipid content diverge when exposed to warmer temperatures. Functional diversity indices change for the six traits under study due to plasticity in response to temperature and reveal overall trait convergence under warmer conditions.

The experimental temperatures we used are non-lethal and lie within a range of moderately high temperatures that can occur frequently in the field during short periods in summer. However, these higher temperatures substantially exceed average daily temperatures and are not experienced for prolonged periods of time and over several generations (Source: Météo France, Vieux-Vy sur Couesnon). This suggests that even a small increase in average temperatures may affect niche partitioning in coexisting species. Warmer temperatures reduced dissimilarity in this parasitoid community, by provoking convergence in important traits, such as resource use and allocation, implying that competitive interactions between species could be altered. For instance, similar development times between parasitoid species shorten the time window for parasitism, which may lead to increased competition for host resources (Price 1972, 1973). This could result both in changes of species abundance and community composition. Moreover, at prolonged warm temperature (i.e., above $25^{\circ} \mathrm{C}$ ), the parasitoid Asobara tabida cannot complete its development (van Strien-van Liempt 1983; Le Lann, unpublished data). Therefore, in a warmer environment, this species may not persist, consequently altering community composition and structure. Finally, host resource quality and availability are also likely affected by warmer temperatures, through changes in body size, development time and reproduction opportunities (Atkinson 1994; Bochdanovits and De Jong 2003). This could potentially affect demographic patterns in host-parasitoid relationships through differential effects on their life-history traits (Hance et al. 2007). The predicted increase in temperature due to local warming might thus affect trait divergence of species communities that potentially compromise community stability and resilience over time. 


\section{Acknowledgements}

We thank André T.C. Dias for helpful advice on earlier versions of this manuscript. This research was supported by grants to C.L.L. from the Ministère de l'Enseignement Supérieur et de la Recherche and Rennes Métropole (France), by the COMPAREVOL program (Marie Curie Excellence Chair, http://comparevol.univ-rennes1.fr/) and by the ECOCLIM program founded by the Région Bretagne (France). B.V. was funded by Netherlands Organisation for Scientific Research (NWO) ALW Grant 816.01.013. The authors declare that they have no

conflict of interest. The experiments comply with the current laws of the countries (The Netherlands and France) in which they were performed. 


\section{References}

Angilletta MJ, Steury TD, Sears MW (2004) Temperature, growth rate, and body size in ectotherms: Fitting pieces of a life-history puzzle. Int Comp Biol 44:498-509

Ashton IW, Miller AE, Bowman WD, Suding KN (2010) Niche complementarity due to plasticity in resource use: plant partitioning of chemical $\mathrm{N}$ forms. Ecology 91:32523260

Askew RR, Shaw MR (1986) Parasitoid communities: their size structure and development. In: Waage J, Greathead D (eds) Insect parasitoids. London Academic Press, London, pp 225-264

Atkinson D (1994) Temperature and organism size - a biological law for ectotherms. Adv Ecol Res 25:1-58

Baffoe KO, Dalin P, Nordlander G, Stenberg JA (2012) Importance of temperature for the performance and biocontrol efficiency of the parasitoid Perilitus brevicollis (Hymenoptera: Braconidae) on Salix. BioControl 57:611-618

Bazzocchi GG, Lanzoni A, Burgio G, Fiacconi MR (2003) Effects of temperature and host on the pre-imaginal development of the parasitoid Diglyphus isaea (Hymenoptera: Eulophidae). Biol Control 26:74-82

Berg MP, Ellers J (2010) Trait plasticity in species interactions: a driving force of community dynamics. Evol Ecol 24:617-629

Berg MP, Kiers ET, Driessen G, Vanderheijden MW, Kooi BW, Kuenen F, Liefting M, Verhoef HA, Ellers J (2010) Adapt or disperse: understanding species persistence in a changing world. Glob Change Biol 16:587-598

Blackburn TM (1991a) A comparative examination of life span and fecundity in parasitoid Hymenoptera. J Anim Ecol 60:151-164 
Blackburn TM (1991b) Evidence for a 'fast-slow' continuum of life-history traits among parasitoid Hymenoptera. Funct Ecol 5:65-74

Bochdanovits Z, De Jong G (2003) Temperature dependence of fitness components in geographical populations of Drosophila melanogaster: changing the association between size and fitness. Biol J Linn Soc 80:717-725

Boivin G (2010) Phenotypic plasticity and fitness in egg parasitoids. Neotrop Entomol 39:457-463

Canham CD, Kobe RK, Latty EF, Chazdon RL (1999) Interspecific and intraspecific variation in tree seedling survival: effects of allocation to roots versus carbohydrate reserves. Oecologia 121:1-11

Carmona CP, Azcárate FM, de Bello F, Ollero HS, Lepš J, Peco B (2012) Taxonomical and functional diversity turnover in Mediterranean grasslands: interactions between grazing, habitat type and rainfall. J Appl Ecol 49:1084-1093

Carton Y, Boulétreau M, van A1phen JJM, van Lenteren JC (1986) The Drosophila parasitic wasps. In: Ashburner M, Carson HL (eds) The genetics and biology of Drosophila (volume 3). Academic Press Inc, London Ltd, pp 347-394

Cavieres G, Sabat P (2008) Geographic variation in the response to thermal acclimation in rufous-collared sparrows: are physiological flexibility and environmental heterogeneity correlated? Funct Ecol 22:509-515

Chase JM, Leibold MA (2003) Ecological niches linking classical and contemporary approaches. University of Chicago Press, Chicago

Clarke A (1993) Seasonal acclimatization and latitudinal compensation in metabolism - Do they exist? Funct Ecol 7:139-149

Cohen JE, JonssonT, Muller CB, Godfray HCJ, Savage VM (2005) Body sizes of hosts and parasitoids in individual feeding relationships. P Nat Acad Sci USA 102:684-689 
Coleman JS, Bazzaz FA (1992) Effects of $\mathrm{CO}_{2}$ and temperature on growth and resource use of co-occurring $\mathrm{C}_{3}$ and $\mathrm{C}_{4}$ annuals. Ecology 73:1244-1259

Colinet H, Boivin G, Hance T (2007) Manipulation of parasitoid size using the temperaturesize rule: fitness consequences. Oecologia 152: 425-433

Dosdall LM, Zalucki MP, Tansey JA, Fur long MJ (2012) Developmental responses of the diamondback moth parasitoid Diadegma semiclausum (Hellén) (Hymenoptera: Ichneumonidae) to temperature and host plant species. B Entomol Res 102:373-384

Eijs IEM, Ellers J, Van Duinen DG (1998) Feeding strategies in drosophilid parasitoids: the impact of natural food resources on energy reserves in females. Ecol Entomol 23:133138

Eijs IEM, Van Alphen JJM (1999) Life history correlations: Why are hymenopteran parasitoids an exception? Ecol Lett 2:27-35

Ellers J (1996) Fat and eggs: An alternative method to measure the trade-off between survival and reproduction in insect parasitoids. Neth J Zool 46:227-235

Ellers J, van Alphen JJM (1997) Life history evolution in Asobara tabida: plasticity in allocation of fat reserves to survival and reproduction. J Evol Biol 10:771-785

Ellers J, van Alphen JJM, Sevenster JG (1998) A field study of size-fitness relationships in the parasitoid Asobara tabida. J Anim Ecol 67:318-324

Ellers J, Sevenster JG, Driessen G (2000) Egg load evolution in parasitoids. Am Nat $156: 650-665$

Elliott NC, Burd JD, Kindler SD, Lee JH (1995) Temperature effects on development of three cereal aphid parasitoids (Hymenoptera: Aphididae). Great Lakes Entomol 28:199-204

Fleury F, Gibert P, Ris N, Allemand R (2009) Ecology and life history evolution of frugivorous Drosophila parasitoids. Adv Parasit 70:3-44 
Foray V, Gibert P, Desouhant E 2011 Differential thermal performance curves in response to different habitats in the parasitoid Venturia canescens. Naturwissenschaften 98:683691

Geister TL, Lorenz MW, Hoffmann KH, Fischer K (2009) Energetics of embryonic development: effects of temperature on egg and hatchling composition in a butterfly. $\mathrm{J}$ Comp Phys B 179:87-98

Gillooly JF, Brown JH, West GB, Savage VM, Charnov EL (2001) Effects of size and temperature on metabolic rate. Science 293:2248-2251

Godfray HJC (1994) Parasitoids Behavioral and Evolutionary Ecology. Princeton, New Jersey, Princeton University Press

Hance T, van Baaren J, Vernon P, Boivin G (2007) Impact of extreme temperatures on parasitoids in a climate change perspective Annu Rev Entom 52:107-126

Harvey JA (2005) Factors affecting the evolution of development strategies in parasitoid wasps: the importance of functional constraints and incorporating complexity. Entomol Exp Appl 117:1-13

Harvey JA, Witjes LMA (2005) Comparing and contrasting life history and development strategies in the pupal hyperparasitoids Lysibia nana and Gelis agilis (Hymenoptera: Ichneumonidae). Appl Entomol Zool 40:309-316

Harvey JA (2008) Comparing and contrasting development and reproductive strategies in the pupal hyperparasitoids Lysibia nana and Gelis agilis (Hymenoptera: Ichneumonidae). Evol Ecol 22:153-166

Harvey JA, Bezemer TM, Gols R, Nakamatsu Y, Tanaka T (2008) Comparing the physiological effects and function of larval feeding in closely-related endoparasitoids (Braconidae: Microgastrinae). Physiol Entomol 33:217-225 
Harvey JA, Poelman EH, Tanaka T (2013) Intrinsic inter- and intraspecific competition in parasitoid wasps. Annu Rev Entom 58:333-351

Hochachka PW, Somero GN (2002) Biochemical adaptation: mechanism and process in physiological evolution. Oxford University Press, Oxford

IPCC (2007) Working group I report, climate change 2007: “the physical science basis”. The fourth assessment report of the intergovernmental panel on climate change, Paris

Irz P, Michonneau F, Oberdorff T, Whittier TR, Lamouroux N, Mouillot D, Argillier C (2007) Fish community comparisons along environmental gradients in lakes of France and northeast USA. Global Ecol Biogeogr 16:350-366

Jervis MA, Heimpel GE, Ferns PN, Harvey JA, Kidd NAC (2001) Life-history strategies in parasitoid wasps: a comparative analysis of "ovigeny". J Anim Ecol 70:442-458

Jervis MA, Ellers J, Harvey JA (2008) Resource acquisition, allocation, and utilization in parasitoid reproductive strategies. Annu Rev Entomol 53:361-385

Jervis MA, Moe A, Heimpel GE (2012) The evolution of parasitoid fecundity: A paradigm under scrutiny. Ecol Lett 15:357-364

Laliberté E, Shipley B (2011) FD: measuring functional diversity from multiple traits, and other tools for functional ecology. R package version 10-11

Le Lann C, Roux O, Serain N, van Alphen JJM, Vernon P, van Baaren J (2011a) Thermal tolerance of sympatric hymenopteran parasitoid species: does it match their seasonal activities? Physiol Entomol 36:21-28

Le Lann C, Wardziak T, van Baaren J, van Alphen JJM (2011b) Plasticity in metabolic rates and life history traits affects foraging behaviour in a parasitic wasp. Funct Ecol $25: 641-651$ 
Le Lann C, Visser B, van Baaren J, van Alphen JJM, Ellers J (2012) Comparing resource exploitation and allocation of two closely related aphid parasitoids sharing the same host. Evol Ecol 26:79-94

Li B, Mills N (2004) The influence of temperature on size as an indicator of host quality for the development of a solitary koinobiont parasitoid. Entomol Exp Appl 110:249-256

Luo LG, Ding GH, Ji X (2010) Income breeding and temperature-induced plasticity in reproductive traits in lizards. J Exp Biol 213:2073-2078

MacArthur RH, Levins R (1967) The limiting similarity convergence and divergence of coexisting species. Am Nat 101:377-385

Mayhew PJ, Blackburn TM (1999) Does parasitoid development mode organize life-history traits in the parasitoid Hymenoptera? J Anim Ecol 68:906-916

Mitchell SE, Halves J, Lampert W (2004) Coexistence of similar genotypes of Daphnia magna in intermittent populations: response to thermal stress. Oikos 106:469-478

Nealis VG, Jones RE, Wellington WG (1984) Temperature and development in host-parasite relationship. Oecologia 61:224-229

Pavoine S, Bonsall M (2011) Measuring biodiversity to explain community assembly: a unified approach. Biol Rev 86:792-812

Pelosse P, Bernstein C, Desouhant E (2007) Differential energy allocation as an adaptation to different habitats in the parasitic wasp Venturia canescens. Evol Ecol 21:669-685

Petchey OL, Beckerman AP, Riede JO, Warren PH (2008) Size, foraging, and food web structure. P Nat Acad Sci USA 105:4191-4196

Price PW (1972) Parasitoids utilizing the same host: adaptive nature of differences in size and form. Ecology 53:190-195

Price P W (1973) Reproductive strategies in parasitoid wasps. Am Nat 107:684-693

Price PW (1974) Strategies for egg production. Evolution 28:76-84 
Qu YF, Li H, Gao JF, Ji X (2011) Embryonic thermosensitivity and hatchling morphology differ between two coexisting lizards. Acta Oecol 37:375-380

R Development Core Team (2010) R: A Language and Environment for Statistical Computing. R Foundation for Statistical Computing, Vienna, Austria ISBN 3900051-07-0 [WWW document]. Available from URL http://wwwR-projectorg [accessed November 2010]

Reale D, McAdam AG, Boutin S, Berteaux D (2003) Genetic and plastic responses of a northern mammal to climate change. P Roy Soc B 270:591-596

Romani R, Isidoro N, Bin F, Vinson SB (2002) Host recognition in the pupal parasitoid Trichopria drosophilae: a morpho-functional approach. Entomol Exp Appl 105:119_ 128

Tilman D (1982) Ressource competition and community structure. Princeton University Press, Princeton

Traynor RE, Mayhew PJ (2005) A comparative study of body size and clutch size across the parasitoid Hymenoptera Oïkos 109:305-316

Valladares F, Wright SJ, Lasso E, Kitajima K, Pearcy RW (2000) Plastic phenotypic response to light of 16 congeneric shrubs from a Panamanian rainforest. Ecology 81:1925-1936

van Baaren J, Le Lann C, van Alphen JJM (2010) Consequences of climate change on aphidbased multi-trophic systems. In Aphid biodiversity under environmental change: Patterns and processes. P Kindlmann, AFG Dixon, JP Michaud (eds), Springer, Dordrecht, pp 55-68

van Strien-van Liempt, WTFH (1983) The competition between Asobara Tabida Nees Von Esenbeck, 1834 and Leptopilina Heterotoma (Thomson, 1862) in multiparasitized hosts. Neth J Zool 33:125-163 
Villéger S, Mason NWH, Mouillot D (2008) New multidimensional functional diversity indices for a multifaceted framework in functional ecology. Ecology 89:2290-2301

Vinson SB (1988) Physiological studies of parasitoids reveal new approaches to the biological control of insect pests. ISI Atlas of Science 1:25-32

Violle C, Enquist BJ, McGill BJ, Jiang L, Albert CH, Hulshof C, Jung V, Messier J (2012) The return of the variance: intraspecific variability in community ecology. Trends Ecol Evol 27:244-252

Visser B, Ellers J (2008) Lack of lipogenesis in parasitoids: A review of physiological mechanisms and evolutionary implications. J Insect Physiol 54:1315-1322

Visser B, Le Lann C, den Blanken FJ, Harvey JA, van Alphen JJM, Ellers J (2010) Loss of lipid synthesis as an evolutionary consequence of a parasitic lifestyle. P Nat Acad Sci USA 107:8677-8682

Visser B, Roelofs D, Hahn DA, Teal PEA, Mariën J, Ellers J (2012) Transcriptional Changes Associated with Lack of Lipid Synthesis in Parasitoids. Gen Biol Evol 4:864-874

Wu GM, Barrette M, Boivin G, Brodeur J, Giraldeau, LA, Hance T (2011) Temperature influences the handling efficiency of an aphid parasitoid through body size-mediated effects. Environ

Entomol 40:737-742 
Table 1 Biological and life history traits of the four solitary Drosophila parasitoids

\begin{tabular}{|c|c|c|c|c|}
\hline Family & Braconidae & Eucoilidae & Diapriidae & Pteromalidae \\
\hline Species & A. tabida & L. heterotoma & T. drosophilae & S. erythromera \\
\hline $\begin{array}{l}\text { Larval developmental } \\
\text { mode }\end{array}$ & & & & \\
\hline Koinobiosis / Idiobiosis & Koinobiont $^{1}$ & Koinobiont $^{1}$ & Idiobiont $^{1}$ & Idiobiont $^{1}$ \\
\hline Host stage attacked & Larvae $^{1}$ & Larvae $^{1}$ & Pupae $^{1}$ & Pupae $^{1}$ \\
\hline Ecto-/Endoparasitism & Endoparasitoid $^{1}$ & Endoparasitoid $^{1}$ & Endoparasitoid $^{1}$ & Ectoparasitoid $^{1}$ \\
\hline Adult resource strategie & & & & \\
\hline Lipogenesis & $\mathrm{No}^{2}$ & Yes $^{2}$ & $\mathrm{No}^{2}$ & $\mathrm{No}^{2}$ \\
\hline Host feeding & $\mathrm{No}^{3}$ & $\mathrm{No}^{3}$ & $\mathrm{No}^{1}$ & $\mathrm{No}^{*}$ \\
\hline Adult resource allocatio & & & & \\
\hline Egg type & Hydropic $^{1}$ & Hydropic $^{1}$ & Anhydropic* & Anhydropic $^{1}$ \\
\hline Arrhenotoky/Thelytoky & Arrhenotoky ${ }^{1}$ & Arrhenotoky ${ }^{1}$ & Arrhenotoky ${ }^{1}$ & Thelytoky $^{1}$ \\
\hline Diapause & Yes $^{1}$ & $\mathrm{No}^{1}$ & $\mathrm{No}^{1}$ & $\mathrm{No}^{1}$ \\
\hline $\begin{array}{c}\text { Host range } \\
\text { (in Western Europe) }\end{array}$ & $\begin{array}{c}\text { Mainly } D . \\
\text { melanogaster, } D . \\
\text { subobscura and } D . \\
\text { obscura }^{1,4}\end{array}$ & $\begin{array}{c}\text { Drosophila, Chymomyza } \\
\text { and } \\
\text { Scaptomyza fly } \\
\text { species }^{1,4}\end{array}$ & $\begin{array}{c}D . \\
\text { melanogaster }^{1,4,5}\end{array}$ & $\begin{array}{c}\text { D. melanogaster, } D \text {. } \\
\text { subobscura, } D \text {. } \\
\text { busckii, D. phalerata, } \\
\text { D. kuntzei and } \\
\text { Musca fly species }\end{array}$ \\
\hline
\end{tabular}

References in table: 1: Carton et al. 1986; 2: Visser et al. 2010; 3 :Eijs et al. 1998; 4: Fleury et al. 2009; 5 : Romani et al. 2002; *: Le Lann, unpublished data. 

Table 2 Linear Mixed Models analyses of resource acquisition, allocation and use in drosophila parasitoids according to their temperature of exposure, developmental mode, species and time (i.e. age of the females: emergence and 7 day-old). F: F-test values, df: degrees of freedom, P: P-values. Dash signs indicate when factors, covariates and their interactions were not included in the models

\begin{tabular}{|c|c|c|c|c|c|c|c|c|c|c|c|c|c|c|c|c|c|c|}
\hline \multirow{2}{*}{$\begin{array}{l}\text { Variables } \\
\text { Factors }\end{array}$} & \multicolumn{3}{|c|}{ Development time } & \multicolumn{3}{|c|}{ Teneral dry mass } & \multicolumn{3}{|c|}{$\begin{array}{c}\text { Teneral lipid } \\
\text { reserves }\end{array}$} & \multicolumn{3}{|c|}{ Teneral egg load } & \multicolumn{3}{|c|}{$\begin{array}{c}\text { Mass-corrected } \\
\text { RMR }\end{array}$} & \multicolumn{3}{|c|}{$\begin{array}{c}\text { Lipid use over } \\
\text { adult life }\end{array}$} \\
\hline & $\mathrm{F}$ & df & $\mathrm{P}$ & $\mathrm{F}$ & df & $\mathrm{P}$ & $\mathrm{F}$ & df & $P$ & $\mathrm{~F}$ & df & $\mathrm{P}$ & $\mathrm{F}$ & $\mathrm{df}$ & $P$ & $\mathrm{~F}$ & $d f$ & $P$ \\
\hline Temperature & 101.26 & 1 & $<0.001$ & 11.26 & 1 & $<0.001$ & 0.02 & 1 & 0.88 & 0.55 & 1 & 0.47 & 8.72 & 1 & $<0.01$ & 1.91 & 1 & 0.17 \\
\hline $\begin{array}{l}\text { Developmental } \\
\text { strategy }\end{array}$ & 30.07 & 1 & $<0.001$ & 2.52 & 1 & 0.12 & 7.47 & 1 & $<0.01$ & 317.19 & 1 & $<0.001$ & 20.45 & 1 & $<0.001$ & 15.87 & 1 & $\begin{array}{c}<0.0 \\
01\end{array}$ \\
\hline $\begin{array}{l}\text { Species within } \\
\text { strategy }\end{array}$ & 47.97 & 2 & $<0.001$ & 4.07 & 2 & $<0.05$ & 4.35 & 2 & $<0.05$ & 20.40 & 2 & $<0.001$ & 55.99 & 2 & $<0.001$ & 7.55 & 2 & $\begin{array}{c}<0.0 \\
01\end{array}$ \\
\hline Time & - & - & - & - & - & - & - & - & - & - & - & - & - & - & - & 1.89 & 1 & 0.17 \\
\hline Covariate & $\mathrm{F}$ & $d f$ & $P$ & $\mathrm{~F}$ & $d f$ & $\mathrm{P}$ & $\mathrm{F}$ & $\mathrm{df}$ & $P$ & $\mathrm{~F}$ & df & $P$ & $F$ & df & $P$ & $\mathrm{~F}$ & $\mathrm{df}$ & $P$ \\
\hline Dry mass & - & - & - & - & - & - & 532.19 & 1 & $<0.001$ & 11.33 & 1 & $<0.001$ & - & - & - & 953.41 & 1 & $\begin{array}{c}<0.0 \\
01\end{array}$ \\
\hline $\begin{array}{l}\text { Interactions } \\
\text { between factors }\end{array}$ & $\mathrm{F}$ & $d f$ & $P$ & $F$ & $d f$ & $P$ & $\mathrm{~F}$ & $d f$ & $P$ & $\mathrm{~F}$ & $d f$ & $\mathrm{P}$ & $\mathrm{F}$ & df & $P$ & $\mathrm{~F}$ & $\mathrm{df}$ & $P$ \\
\hline $\begin{array}{l}\text { Developmental } \\
\text { strategy*Temperature }\end{array}$ & 0.04 & 1 & 0.85 & 0.35 & 1 & 0.56 & 5.66 & 1 & $<0.05$ & 4.06 & 1 & 0.05 & 3.33 & 1 & 0.075 & 0.03 & 1 & 0.86 \\
\hline $\begin{array}{l}\text { Species within } \\
\text { strategy*Temperature }\end{array}$ & 1.83 & 2 & 0.17 & 3.19 & 2 & $<0.05$ & 0.55 & 2 & 0.582 & 0.88 & 2 & 0.36 & 8.46 & 2 & $<0.001$ & 7.50 & 2 & $\begin{array}{c}<0.0 \\
01\end{array}$ \\
\hline Temperature*Time & - & - & - & - & - & - & - & - & - & - & - & - & - & - & - & 0.01 & 1 & 0.94 \\
\hline
\end{tabular}




\begin{tabular}{|c|c|c|c|c|c|c|c|c|c|c|c|c|c|c|c|c|c|c|}
\hline \multirow{2}{*}{$\begin{array}{l}\text { Variables } \\
\text { Developmental } \\
\text { strategy*Time }\end{array}$} & \multicolumn{3}{|c|}{ Development time } & \multicolumn{3}{|c|}{ Teneral dry mass } & \multicolumn{3}{|c|}{$\begin{array}{c}\text { Teneral lipid } \\
\text { reserves }\end{array}$} & \multicolumn{3}{|c|}{ Teneral egg load } & \multicolumn{3}{|c|}{$\begin{array}{c}\text { Mass-corrected } \\
\text { RMR } \\
\end{array}$} & \multicolumn{3}{|c|}{$\begin{array}{l}\text { Lipid use over } \\
\text { adult life }\end{array}$} \\
\hline & & & & & & & & & & & & & & & & 25.77 & 1 & $\begin{array}{c}<0.0 \\
01\end{array}$ \\
\hline $\begin{array}{l}\text { Species within } \\
\text { strategy*Time }\end{array}$ & - & - & - & - & - & - & - & - & - & - & - & - & - & - & - & 11.11 & 2 & $\begin{array}{c}<0.0 \\
01\end{array}$ \\
\hline $\begin{array}{l}\text { Interactions } \\
\text { between factor and } \\
\text { covariate }\end{array}$ & $\mathrm{F}$ & df & $P$ & $\mathrm{~F}$ & df & $P$ & $\mathrm{~F}$ & df & $P$ & $F$ & df & $P$ & $\mathrm{~F}$ & $d f$ & $P$ & $\mathrm{~F}$ & df & $\mathrm{P}$ \\
\hline $\begin{array}{l}\text { Developmental } \\
\text { strategy*Dry mass }\end{array}$ & - & - & - & - & - & - & 15.92 & 2 & $<0.001$ & - & - & - & - & - & - & 19.78 & 1 & $\begin{array}{c}<0.0 \\
01\end{array}$ \\
\hline $\begin{array}{l}\text { Species within } \\
\text { strategy*Dry mass }\end{array}$ & - & - & - & - & - & - & - & - & - & - & - & - & - & - & - & 7.83 & 2 & $\begin{array}{c}<0.0 \\
01\end{array}$ \\
\hline Time*Dry mass & & & & & & & & & & & & & & & & 24.6 & 1 & $\begin{array}{c}<0.0 \\
01\end{array}$ \\
\hline
\end{tabular}


Fig. 1 Dry mass at emergence $(\mathrm{mg})$ (mean $\pm \mathrm{SE}, \mathrm{N}=5-46$ per species per temperature) (a), development time (days) (mean $\pm \mathrm{SE}, \mathrm{N}=5-89$ per species per temperature) (b), lipid content at emergence (mg) (mean $\pm \mathrm{SE}, \mathrm{N}=5$-46 per species per temperature) (c) and egg load at emergence (number of mature eggs) (mean $\pm \mathrm{SE}, \mathrm{N}=5$-23 per species per temperature) (d) at two temperatures $\left(20\right.$ and $\left.23^{\circ} \mathrm{C}\right)$ of the Drosophila parasitoids: Asobara tabida (AS), Leptopilina heterotoma (LE), Spalangia erythromera (SP) and Trichopria drosophilae (TR). Solid and dashed lines represent thermal reaction norms of larval koinobiont and pupal idiobiont species, respectively

Fig. 2 Mass-corrected Resting Metabolic Rate (RMR) ( $\mu \mathrm{L} \cdot \mathrm{CO}_{2} \cdot \mathrm{h}^{-1} \cdot \mathrm{mg}^{-1}$ ) (one day-old) (mean $\pm \mathrm{SE}, \mathrm{N}=17-28$ per species per temperature) (a) and proportion of lipids used over time (Emergence and 7 days-old) (mean $\pm \mathrm{SE}, \mathrm{N}=4-46$ per species per temperature) (b) at two temperatures $\left(20\right.$ and $23^{\circ} \mathrm{C}$ ) of the Drosophila parasitoids: Asobara tabida (AS), Leptopilina heterotoma (LE), Spalangia erythromera (SP) and Trichopria drosophilae (TR). Solid and dashed lines represent thermal reaction norms of larval koinobiont and pupal idiobiont species, respectively

Fig. 3 Rao's quadratic entropy indices of diversity (RaoQ; open square symbol) and Functional richness (FRic; black diamond symbol) based on six species traits (development time, dry mass, lipid content and egg load at emergence, mass-corrected RMR and the amount of lipid used or produced between emergence and 7 days) in the community of Drosophila parasitoids exposed at two temperatures $\left(20\right.$ and $23^{\circ} \mathrm{C}$ ) (RaoQ: $20^{\circ} \mathrm{C}: 0.55 ; 23^{\circ} \mathrm{C}: 0.38$ / FRic: $\left.20^{\circ} \mathrm{C}: 0.25 ; 23^{\circ} \mathrm{C}: 0.02\right)$ 
Fig. 1
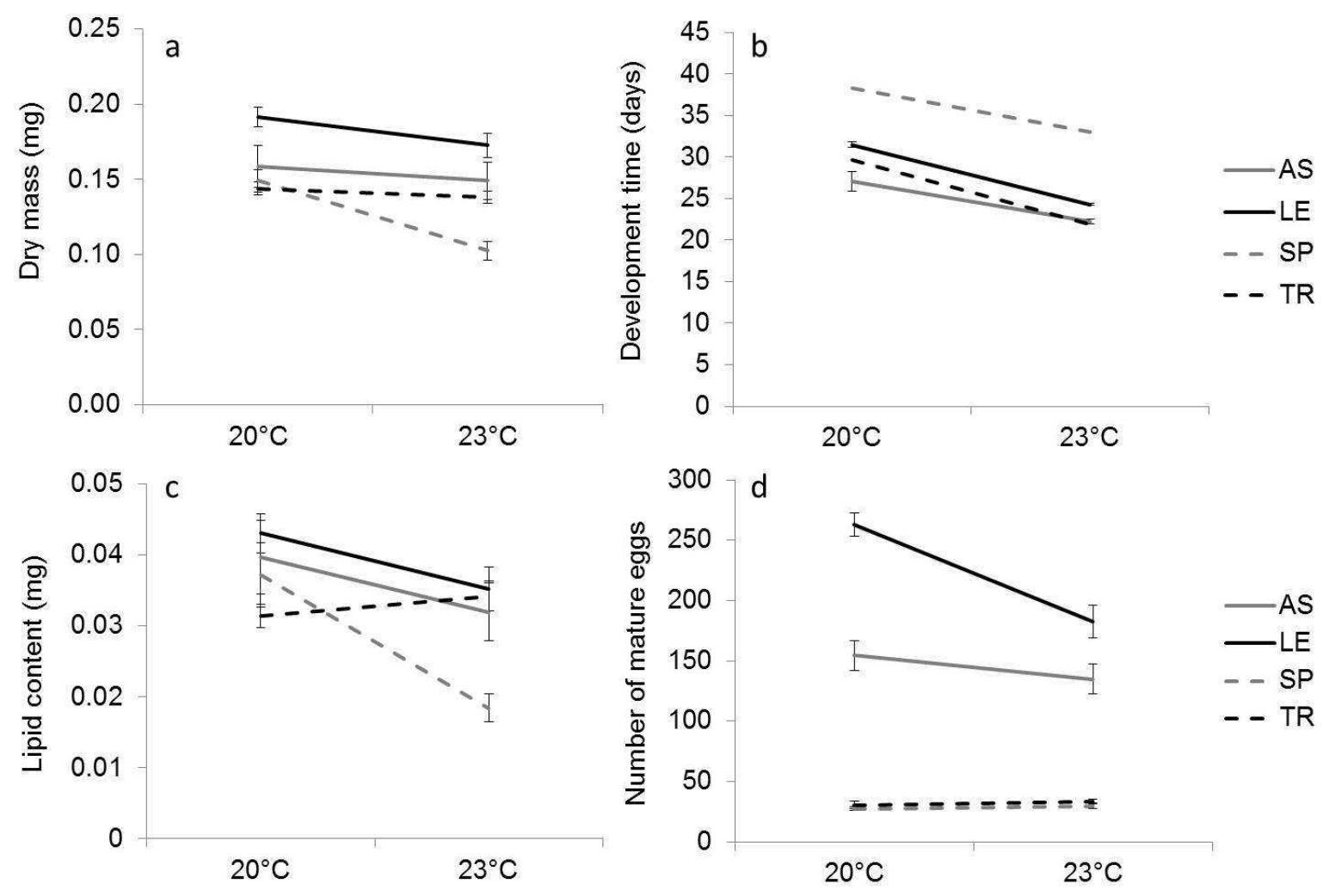
Fig. 2
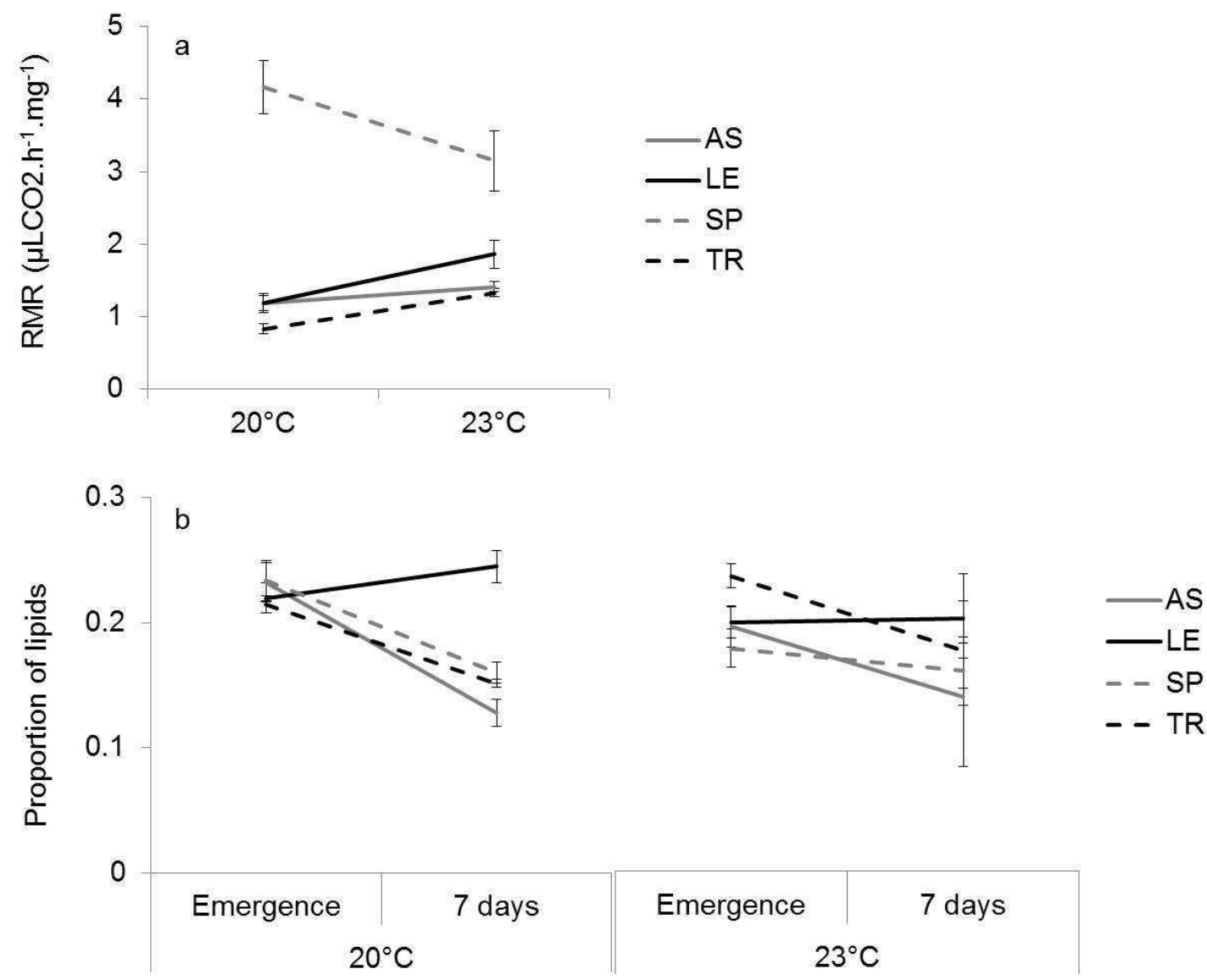
Fig. 3

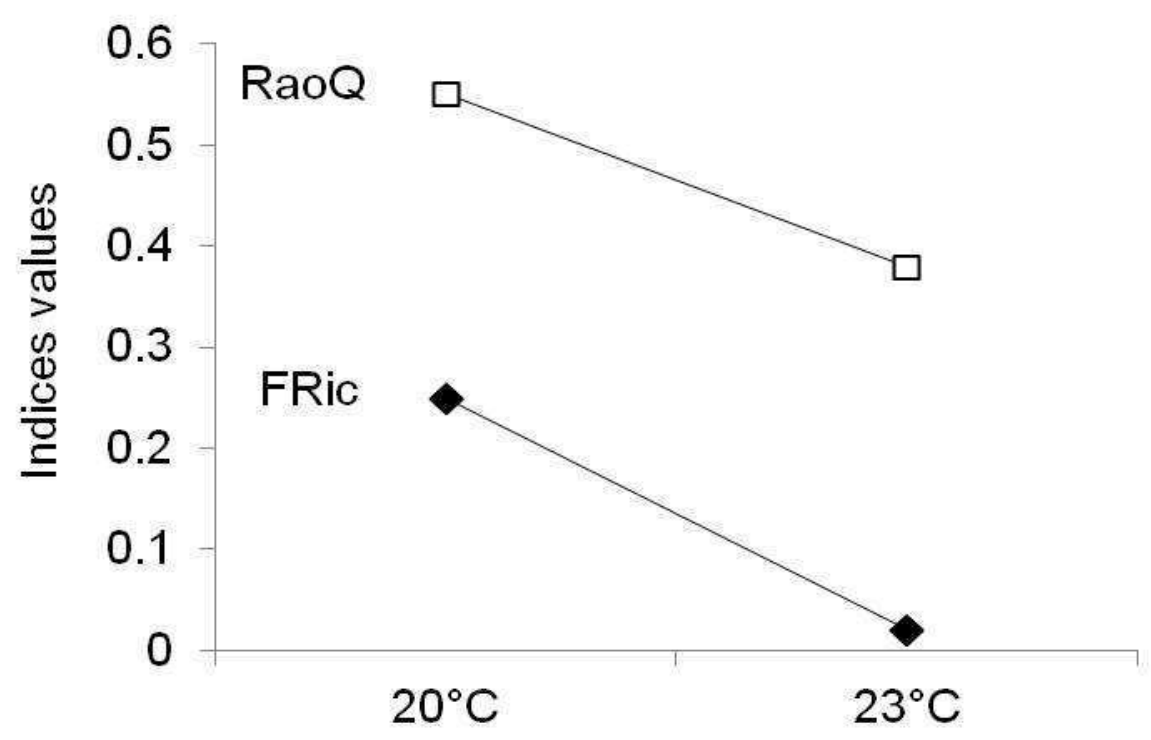

